\title{
Comparative study of non-descent vaginal hysterectomy and laparoscopy assisted vaginal hysterectomy
}

\author{
Surendra Nath Soren, Ghanashyam Chattar, Jitendra Kumar Dash*
}

Department of Obstetrics and Gynecology, MKCG Medical College and Hospital, Brahmapur, Odisha, India

Received: 29 December 2020

Accepted: 13 January 2021

\section{*Correspondence:}

Dr. Jitendra Kumar Dash,

E-mail: dashjitendra1985@gmail.com

Copyright: (c) the author(s), publisher and licensee Medip Academy. This is an open-access article distributed under the terms of the Creative Commons Attribution Non-Commercial License, which permits unrestricted non-commercial use, distribution, and reproduction in any medium, provided the original work is properly cited.

\section{ABSTRACT}

Background: We aimed to assess and compare intra operative and post-operative parameters and complications associated with non-descent vaginal hysterectomy group (NDVH) and laparoscopic assisted vaginal hysterectomy group (LAVH).

Methods: In this observational study 100 patients with uterine size not exceeding 12 weeks of gravid uterus, adequate uterine mobility, fibroid uterus, dysfunctional uterine bleeding, chronic cervicitis, adenomyosis and post-menopausal bleeding were divided into two groups to undergo either NDVH and LAVH. Their intra-operative and post-operative parameters were compared.

Results: The mean operating time was significantly less in NDVH group as compared to LAVH group cases (65.44 vs 83.12 mins; $\mathrm{p}<0.01)$. Blood loss $(210.22 \mathrm{vs} 261.58 \mathrm{ml}$; $\mathrm{p}-0.03)$ during the procedure and drop in haemoglobin (1.22 vs $1.62 \mathrm{gm} \%$; p-0.08) was also lower with NDVH group as compared to LAVH group respectively. Requirement of blood transfusion, adnexotomy and incidence of anaesthesia related complications were similar between the two study groups. Median VAS score was significantly less in NDVH group as compared to LAVH group at immediate post-op period and at day 1 respectively $(\mathrm{p}<0.01)$. We observed a comparable mean hospital stay for the patients in the two study groups $(5.52 \pm 1.33$ vs $6.01 \pm 1.39$ days, $\mathrm{p}$ value $=0.71)$.

Conclusions: Based on the results of the present study, we conclude that NDVH is safe and should be offered as the first surgical choice in women with uterine enlargement due to benign pathology and non-prolapsed uterus.

Keywords: Fibroid uterus, Laparoscopic hysterectomy, Non-descent vaginal hysterectomy

\section{INTRODUCTION}

Traditionally, the uterus has been removed by abdominal route which gives the chance to inspect the ovaries and vaginal route was reserved for pelvic organ prolapse. Today the emphasis is on minimally invasive surgery, which resulted in an interest for vaginal hysterectomy (VH) for non-prolapse indications. This technique is called the non-descent vaginal hysterectomy (NDVH), the scarless hysterectomy. ${ }^{1}$ The laparoscopic approach may be used either to facilitate the ease of vaginal delivery of uterus as in laparoscopy assisted vaginal hysterectomy (LAVH) or it may be carried out completely till final detachment of uterus from pelvic wall i.e., total laparoscopic hysterectomy (TLH). There are no definite criteria to select the route of hysterectomy for benign gynaecological conditions. The route is often decided by personal preferences, size of uterus and associated conditions like adhesions etc. ${ }^{2}$ Laparoscopic hysterectomy has the advantage of visualization of pelvic structure and occasional dissection and adhesiolysis. But laparoscopic surgeries require technologically advanced setup and sophisticated instruments.

It also increases the financial burden for the patient in comparison to vaginal hysterectomy. ${ }^{3}$ In the present study, we aimed to assess and compare intra operative and post-operative parameters and complications associated with LAVH and NDVH. 


\section{METHODS}

\section{Study design and sample population}

This was an observational cross-sectional study conducted in the Department of Obstetrics \& Gynaecology, Maharaja Krushna Chandra Gajapati Medical College and Hospital Brahmapur, Ganjam, Odisha from the period October 2018 till September 2020. We included patients aged more than 30 years, uterine size not exceeding 12 weeks of gravid uterus, adequate uterine mobility, fibroid uterus, dysfunctional uterine bleeding, chronic cervicitis, adenomyosis and post-menopausal bleeding. We decided to exclude patients who had restricted uterine mobility, prolapse uterus, total abdominal hysterectomy, complex adnexal mass and those with previous 2 or more LSCS. A total 100 patients attending gynaecology OPD of this institution indicated for hysterectomy who consented to participate in the study after fulfilling inclusion and exclusion criteria were enrolled for the study. Patients were divided into two groups comprised of 50 patients each who were operated by two different routes of hysterectomy, after adjusting demographic and co-morbid conditions. The two groups were group A: non-descent vaginal hysterectomy group (NDVH) and group B: laparoscopic assisted vaginal hysterectomy group (LAVH).

\section{Data collection and data analysis}

Using a pre-designed semi-structured study proforma, patient related variables were noted. Hysterectomies by both the routes was performed as per present standard hospital protocols and steps. Operating time for vaginal hysterectomy was calculated from the start of incision at cervicovaginal junction to the closure of vault. For LAVH operating time was calculated from the insertion of veres needle to closure of port insertion site. Blood loss was calculated by noting the number of mops used along with the blood collected in the suction bottles during surgery. Post-op day $3, \mathrm{Hb} \%$ was measured and fall in haemoglobin was noted. Any requirement of blood transfusion was also recorded. The comfort of the patient was noted by post-op analgesia requirement which was based on visual analogue scale (VAS).

Post-operative complications like fever, urinary tract infection, vaginal cuff cellulites, and abdominal wound infection was noted. Patients of NDVH were discharged on day 4 after per speculum examination of the vaginal vault. LAVH were discharged on day 3 once they were fit to be discharge and they were followed up on day 5 for wound examination and suture removal.

The quantitative data was represented as their mean \pm SD. Categorical and nominal data was expressed in percentage. The t-test was used for analysing quantitative data, or else non parametric data was analyzed by Mann Whitney test and categorical data was analyzed by using chi-square test. The significance threshold of $\mathrm{p}$ value was set at $<0.05$. All analysis was carried out by using SPSS software version 21 .

\section{RESULTS}

Study included a total of 100 patients indicated for hysterectomy, equally divided in the two study groups. Mean age of the study population was 46.71 years and it was similar between the two study groups (Table 1).

Table 1: Baseline characteristics of the patients included in the study.

\begin{tabular}{|c|c|c|c|}
\hline Variables & $\begin{array}{l}\text { Non-descent vaginal } \\
\text { hysterectomy group }(\mathrm{n}=\mathbf{5 0})\end{array}$ & $\begin{array}{l}\text { Laparoscopic assisted vaginal } \\
\text { hysterectomy group }(n=50)\end{array}$ & P value \\
\hline Mean age (years) & $44.72 \pm 7.99$ & $48.69 \pm 8.41$ & 0.3 \\
\hline \multicolumn{4}{|l|}{ Socio-economic status } \\
\hline Upper & $1(2 \%)$ & $1(2 \%)$ & \multirow{3}{*}{0.77} \\
\hline Middle & $13(26 \%)$ & $10(20 \%)$ & \\
\hline Lower & $36(72 \%)$ & $39(78 \%)$ & \\
\hline Mean BMI (kg/m2) & $24.3 \pm 3.17$ & $23.7 \pm 3.15$ & 0.91 \\
\hline \multicolumn{4}{|l|}{ Gravidity } \\
\hline Nulli-gravida & $2(4 \%)$ & $1(2 \%)$ & \multirow{3}{*}{0.78} \\
\hline P1-P4 & $43(86 \%)$ & $45(90 \%)$ & \\
\hline$\geq \mathrm{P} 5$ & $5(10 \%)$ & $4(8 \%)$ & \\
\hline History of LSCS & $14(28 \%)$ & $9(18 \%)$ & 0.34 \\
\hline \multicolumn{4}{|l|}{ Indication of surgery } \\
\hline Fibroid & $29(58 \%)$ & $27(54 \%)$ & \multirow{5}{*}{0.49} \\
\hline Abnormal uterine bleeding & $10(20 \%)$ & $6(12 \%)$ & \\
\hline Adenomyosis & $6(12 \%)$ & $11(22 \%)$ & \\
\hline Polyp & $3(6 \%)$ & $5(10 \%)$ & \\
\hline Ovarian cyst & $2(4 \%)$ & $1(2 \%)$ & \\
\hline
\end{tabular}


Table 2: Comparison of intra-operative parameters.

\begin{tabular}{|c|c|c|c|}
\hline Variables & $\begin{array}{l}\text { Non-descent vaginal } \\
\text { hysterectomy group }(\mathrm{n}=\mathbf{5 0})\end{array}$ & $\begin{array}{l}\text { Laparoscopic assisted vaginal } \\
\text { hysterectomy group }(\mathrm{n}=\mathbf{5 0})\end{array}$ & P value \\
\hline Operating time (mins) & $65.44 \pm 14.5$ & $83.12 \pm 13.78$ & $<0.01$ \\
\hline Blood loss (ml) & $210.22 \pm 101.2$ & $261.58 \pm 95.6$ & $<0.05$ \\
\hline Drop in hemoglobin (gm\%) & $1.22 \pm 0.81$ & $1.62 \pm 0.79$ & 0.08 \\
\hline Uterine weight (gm) & $191.23 \pm 101.9$ & $201.34 \pm 89.98$ & 0.33 \\
\hline Uterine size $(\mathbf{c m})$ & $11.36 \pm 3.17$ & $11.68 \pm 4.58$ & 0.68 \\
\hline Need for blood transfusion & $7(14 \%)$ & $9(18 \%)$ & 0.76 \\
\hline Adnexotomy & $11(22 \%)$ & $20(40 \%)$ & 0.08 \\
\hline \multicolumn{4}{|l|}{ Anesthetic complications } \\
\hline $\begin{array}{l}\text { Failure of spinal anesthesia (need for } \\
\text { general anesthesia) }\end{array}$ & $0(0 \%)$ & $1(2 \%)$ & 0.81 \\
\hline Headache & $3(6 \%)$ & $3(6 \%)$ & 0.99 \\
\hline Vomiting & $0(0 \%)$ & $2(4 \%)$ & 0.67 \\
\hline
\end{tabular}

Table 3: Comparison post-operative characteristics of the patients.

\begin{tabular}{|llll|}
\hline Variables & $\begin{array}{l}\text { Non-descent vaginal } \\
\text { hysterectomy group }(\mathbf{n = 5 0 )}\end{array}$ & $\begin{array}{l}\text { Laparoscopic assisted vaginal } \\
\text { hysterectomy group }(\mathbf{n = 5 0 )}\end{array}$ & P value \\
\hline Post-operative complications & & & 0.77 \\
\hline Fever & $6(12 \%)$ & $8(16 \%)$ & 0.71 \\
\hline Urinary tract infection & $3(6 \%)$ & $5(10 \%)$ & 0.11 \\
\hline Urinary bladder injury & $0(0 \%)$ & $4(8 \%)$ & 0.11 \\
\hline Ileus & $0(0 \%)$ & $4(8 \%)$ & $<0.01$ \\
\hline Pain on VAS* & & $7(\mathrm{IQR} 1.4)$ & $<0.01$ \\
\hline Immediate post-operatively & $6(\mathrm{IQR} 1.2)$ & $6(\mathrm{IQR} 1.6)$ & 0.71 \\
\hline Post-operative day 1 & $5(\mathrm{IQR} 1.4)$ & $6.01 \pm 1.39$ & \\
\hline Length of hospital stay (days) & $5.52 \pm 1.33$ & &
\end{tabular}

Other baseline variables like BMI, socioeconomic status and gravid status was similar among patients of the two study groups. History of previous LSCS was given by $23 \%$ cases with no difference between study groups. Most common indication for hysterectomy was fibroid (56\%) followed by adenomyosis (17\%) and abnormal uterine bleeding (16\%). Polyp and ovarian cyst was indication in $8 \%$ and $3 \%$ cases respectively.

As shown in Table 2, mean operating time was significantly less in NDVH group as compared to LAVH group cases (65.44 vs 83.12 mins; p<0.01). Blood loss ( 210.22 vs $261.58 \mathrm{ml} ; \mathrm{p}=0.03)$ during the procedure and drop in haemoglobin (1.22 vs 1.62 gm\%; p=0.08) was also lower with NDVH group as compared to LAVH group respectively. Requirement of blood transfusion, adnexotomy and incidence of anaesthesia related complications were similar between the two study groups. Post-operatively fever (14\%), urinary tract infection $(8 \%)$ and urinary bladder injury (4\%) and ileus (4\%) were some common complications, with similar distribution between the two groups (Table 3). Median VAS score was significantly less in NDVH group as compared to LAVH group at immediate post-op period and at day 1 respectively $(\mathrm{p}<0.01)$. We observed a comparable mean hospital stay for the patients in the two study groups $\quad(5.52 \pm 1.33$ vs $6.01 \pm 1.39$ days, $p$ value $=0.71$ ).

\section{DISCUSSION}

In the absence of uterine prolapse, most gynaecologists prefer the abdominal to vaginal route of hysterectomy. The common limitations for vaginal hysterectomy in nonpro- lapsed uterus include size of the uterus, nulliparity, previous pelvic surgery or lower segment caesarean section (LSCS), pelvic adhesions and endometriosis, last but not the least limited exposure during the learning phase of their career. The factors that may influence the route of hysterectomy for any surgical indication include uterine size, mobility, accessibility and pathology confined to the uterus. Multiparity, lax tissues following multiple deliveries and decreased tissue tensile strength provide comfort to vaginal surgeon even in the presence of uterine enlargement. ${ }^{4}$

We observed that the mean operating time, blood loss and drop in hemoglobin was significantly less in NDVH group as compared to LAVH group patients. Nambiar and colleagues observed that operating time was lesser in NDVH group. ${ }^{5}$ Similar to our findings, operating time in their study was $87.36 \pm 16.32$ minutes in LAVH group as 
compared to and $67.38 \pm 16.77$ minutes in NDVH, p value $<0.001$ ). They also found the intraoperative blood loss to be significantly less in NDVH group as compared to LAVH group patients $(269.85 \pm 103.85 \mathrm{ml}$ vs $219.05 \pm 84.37 \mathrm{ml}, \mathrm{p}$ value $=0.026)$. Shiragur et al observed mean operative time in LAVH was 240.6 minutes and in NDVH 168.3 minutes $(\mathrm{p}<0.01){ }^{6}$

As for the pain assessment, we found that the median VAS score was significantly less in NDVH group as compared to LAVH group at immediate post-op period and at day 1 respectively. However, mean hospital stay was comparable between the study group. Similar observations were made by Nambiar et al who found the pain score was in the immediate postoperative period to be $7.04 \pm 0.46$ in the LAVH group and $6.12 \pm 0.72$ in the NDVH group ( $\mathrm{p}$ value $<0.001$ ). Contrary to our findings, Murali et al and Kansara et al observed similar postoperative analgesia requirement for the patients in the two groups. ${ }^{7,8}$ But they did find that the post-operative hospital stay was similar, which is similar to our results.

In our experience, post-operative fever and urinary tract infection was comparable between NDVH and LAVH group while incidence of ileus and bladder injury was associated with NDVH. Nambiar et al in their study found that complications like bladder hematoma and paralytic ileus were seen was seen only in LAVH group. Uikey et al in their study reported that incidence of complications was least in the NDVH group. ${ }^{9}$ Murali et al and Kansara et al in their studies also showed that postoperative complications were similar in both groups.

\section{CONCLUSION}

Based on the results of the present study, we conclude that NDVH is safe and should be offered as the first surgical choice in women with uterine enlargement due to benign pathology and non-prolapsed uterus. Our study shows that NDVH is associated with significantly less intraoperative blood loss and shorter operating time. Patients reported less discomfort after NDVH in immediate postoperative period. On the contrary, LAVH was associated with higher risk of bladder injury and post-op ileus.

\section{Funding: No funding sources} Conflict of interest: None declared

Ethical approval: The study was approved by the Institutional Ethics Committee

\section{REFERENCES}

1. Balakrishnan D, Dibyajyoti G. A comparison between non descent vaginal hysterectomy and total abdominal hysterectomy. J Clin Diagn Res. 2016;10(1):11-4

2. Garry R. The future of hysterectomy. BJOG. 2005;112:133-9.

3. Fuzayel AB, Bhadra B, Choudhury N, Shyam DJ, Total laparoscopic hysterectomy versus non -descent vaginal hysterectomy: An observational study. International Journal of Recent Trends in Science and Technology. 2017;24(2):40-3.

4. Gayathri KB, Sajana G, Manjusha P. Non descent vaginal hysterectomy for benign gynaecological disease: an institutional study on safety and feasibility from South India. J Dent Med Sci. 2017;16(11):59-63

5. Nambiar MJ, Dawson S, Muralidhar V. A comparative study between laparoscopic assisted vaginal hysterectomy (LAVH) vs. non descent vaginal hysterectomy (NDVH) in patients with benign gynecological pathology. Int J Clinic Obstet Gynaecol. 2017;1(2):65-8.

6. Shiragur SS, Rajammal B. Comparative clinical study of laparoscopic assisted vaginal hysterectomy and non-descent vaginal hysterectomy.

7. Murali MS, Khan A. A Comparative Study of Nondescent Vaginal Hysterectomy and Laparoscopic Hysterectomy. J Obstet Gynecol Ind. 2019;69(4):369-73.

8. Kansara V, Chaudhari J, Desai A. A comparative study of non-descent vaginal hysterectomy and total laparoscopic hysterectomy. Int J Reprod Contracept Obstet Gynecol. 2020;9:777-81.

9. Uikey P, Wankhede TM, Tajne MP. The route of hysterectomy: a comparative study between abdominal hysterectomy (AH), non-descent vaginal hysterectomy (NDVH), and laparoscopic assisted vaginal hysterectomy (LAVH). Int J Reprod Contracept Obstet Gynecol. 2018;7(10):4022-8.

Cite this article as: Soren SN, Chattar G, Dash JK. Comparative study of non-descent vaginal hysterectomy and laparoscopy assisted vaginal hysterectomy. Int J Reprod Contracept Obstet Gynecol 2021;10:532-5. 